\title{
Carbon monoxide in breath in relation to smoking and carboxyhaemoglobin levels
}

\author{
NICHOLAS J WALD, MARIANNE IDLE, JILLIAN BOREHAM, AND ALAN BAILEY \\ From ICRF Cancer Epidemiology and Clinical Trials Unit, Radcliffe Infirmary, Oxford, and \\ BUPA Medical Centre, London
}

ABSTRACT Carboxyhaemoglobin (COHb) levels were studied in 11249 men. The distribution among the 2613 men who smoked cigarettes was well separated from that in 6641 non-smokers (including ex-smokers). The distribution for 2005 cigar and pipe smokers was intermediate, though some of the highest $\mathrm{COHb}$ levels occurred in cigar smokers. Using a $\mathrm{COHb}$ cut-off level of $2 \%, 81 \%$ of cigarette smokers, $35 \%$ of cigar and pipe smokers, and $1.0 \%$ of non-smokers had raised $\mathrm{COHb}$ levels. In a subsidiary experiment alveolar air samples were collected from 162 smokers and 25 non-smokers using a simple breath sampling technique. Carbon monoxide concentrations in alveolar breath were highly correlated with $\mathrm{COHb}$ levels $(\mathrm{r}=0.97)$ indicating that $\mathrm{COHb}$ levels can be estimated reliably by measuring the concentration of carbon monoxide in breath. Alveolar carbon monoxide measurement is thus a simple method of estimating whether a person is likely to be a smoker.

The level of carboxyhaemoglobin $(\mathrm{COHb})$ in the blood has been shown to be a useful marker of tobacco smoke absorption, ${ }^{1-6}$ and for this reason there are epidemiological and clinical reasons for performing $\mathrm{COHb}$ measurements. The precise distributions of $\mathrm{COHb}$ levels in smokers and nonsmokers, and the extent to which they overlap, are not well known. We therefore investigated this in over 11000 men. We also investigated the measurement of carbon monoxide (CO) in alveolar breath using a portable analyser, as an indirect measure of the $\mathrm{COHb}$ level which avoids the inconvenience of taking blood samples.

\section{Methods}

CARBOXYHAEMOGLOBIN AND SMOKING

The main study population consisted of 11249 men aged 35-64 years who attended the BUPA Medical Centre in London for a comprehensive health screening examination. On arrival at the Medical Centre, between 1100 and 1700 hours, men were asked about their usual and recent smoking habits, and were not forewarned about the study. The time of smoking each cigarette, cigar, or pipe since waking was recorded. Each

Address for reprint requests: Dr NJ Wald, ICRF Cancer Epidemiology and Clinical Trials Unit, Radcliffe Infirmary, Oxford OX2 6HE. man supplied a sample of venous blood and the $\mathrm{COHb}$ value was determined using the IL $182 \mathrm{CO}$ Oximeter, as previously described. ${ }^{7}$

Table 1 shows the number of men according to smoking category, together with the definitions used when classifying smoking habits.

\section{ALVEOLAR CARBON MONOXIDE AND}

CARBOXYHAEMOGLOBIN

The investigation of alveolar $\mathrm{CO}$ and $\mathrm{COHb}$ was performed on a subgroup of 187 men (162 smokers

Table 1 Study subjects divided according to smoking category

\begin{tabular}{lr}
\hline Smoking category & $\begin{array}{c}\text { Number } \\
\text { of men }\end{array}$ \\
\hline Smokers & 2083 \\
Manufactured cigarettes only & 530 \\
Manufactured cigarettes and pipes and/or cigars & 629 \\
Pipes only & 1106 \\
Cigars only & 270 \\
Pipes and cigars only & 4608 \\
All smokers & 3380 \\
Non-smokers & 3261 \\
Ex-smokers & 6641 \\
Lifelong non-smokers & 11249 \\
All non-smokers & \\
Total number of men & \\
\hline A smoker is taken to mean someone who usually smokes more than one \\
cigarette a day, or more than two cigars or 0.25 oz tobacco a week. An \\
ex-smoker is someone who has been a smoker for at least one year \\
sometime in the past and is no longer a smoker. A lifelong non-smoker \\
is someone who has never smoked for as long as one year.
\end{tabular}


and 25 non-smokers) in the main study. Three samples of alveolar breath were collected at twominute intervals within about five minutes after blood was taken for the $\mathrm{COHb}$ estimation. Without a previous deep inspiration, each subject held his breath for 20 seconds, then exhaled steadily via a respiratory valve and plastic tube $1 \mathrm{~m}$ long and $17 \mathrm{~mm}$ internal diameter into a three-litre anaesthetic balloon. The gas in the proximal end of the plastic tube was taken to be alveolar breath and this was sampled by means of a small side tube $5 \mathrm{~mm}$ away from the mouthpiece. CO measurements were performed using an Ecolyser (Energetics Science Inc, NY). This is a portable instrument $(33 \mathrm{~cm} \times 19 \mathrm{~cm} \times 18 \mathrm{~cm}$, and weighing $4 \mathrm{~kg}$ ), which can be operated on the mains or by means of its own rechargeable batteries. The $\mathrm{CO}$ measurement is based on the rate of conversion of $\mathrm{CO}$ to $\mathrm{CO}_{2}$ when passed over a catalytically active electrode in an aqueous electrolyte. All alveolar breath samples were analysed immediately after collection to avoid mixing with dead space gas. The mean of the last two readings was recorded, to the nearest $0.25 \mathrm{ppm}$. The calibration of the instrument was checked between each set of readings using a sample of known concentration of $\mathrm{CO}$ gas.

It is known that alcohol vapour can affect the response of the Ecolyser and this was confirmed. Subjects were asked if they had drunk alcohol on the day they were seen and were excluded if they had done so.

\section{Results}

CARBOXYHAEMOGLOBIN AND SMOKING

Table 2 shows the $\mathrm{COHb}$ distribution in nonsmokers (including both lifelong non-smokers and ex-smokers) and men who smoked cigarettes only. There is very little overlap between the two distributions; for example $81 \%$ of the cigarette smokers had $\mathrm{COHb}$ levels equal to or greater than $2 \%$ but only $1 \%$ of non-smokers had $\mathrm{COHb}$ levels as high as this.

The distributions of $\mathrm{COHb}$ levels from lifelong non-smokers and ex-smokers were very similar, although a slightly higher proportion of exsmokers had COHb levels equal to or greater than $2.0 \%(1.2 \%$ and $0.7 \%$ of ex-smokers and lifelong non-smokers respectively), suggesting that men claiming to be ex-smokers were more likely to have smoked within a day or so of the test than men claiming to be lifelong non-smokers. For example, the only four "non-smokers" with $\mathrm{COHb}$ levels greater than $5.0 \%$ were ex-smokers,
Table 2 Number and percentage of non-smokers and smokers of cigarettes only according to $\mathrm{COHb}$ level

\begin{tabular}{|c|c|c|c|c|}
\hline \multirow[t]{3}{*}{$\mathrm{COHb}$} & \multicolumn{2}{|c|}{ Non-smokers } & \multirow{2}{*}{\multicolumn{2}{|c|}{$\begin{array}{l}\text { Smokers of } \\
\text { cigarettes only }\end{array}$}} \\
\hline & \multirow{2}{*}{ Number } & \multirow{2}{*}{$\%$} & & \\
\hline & & & Number & $\%$ \\
\hline 0.0 & 687 & 10 & 5 & 0.24 \\
\hline 0.5 & 4161 & 63 & 92 & $4 \cdot 4$ \\
\hline $1 \cdot 0$ & 1562 & 24 & 144 & 6.9 \\
\hline $1.5-$ & 167 & 2.5 & 84 & 4.0 \\
\hline $2 \cdot 0$ & 41 & 0.62 & 112 & $5 \cdot 4$ \\
\hline $2 \cdot 5$ & 8 & $0 \cdot 12$ & 101 & $4 \cdot 8$ \\
\hline $3 \cdot 0$ & 11 & 0.17 & 246 & 12 \\
\hline $4 \cdot 0$ & $2 *$ & 0.03 & 632 & 30 \\
\hline 6.0 & $1^{*}$ & 0.015 & 442 & 21 \\
\hline $8 \cdot 0$ & $1^{*}$ & 0.015 & 169 & $8 \cdot 1$ \\
\hline 10.0 & 0 & - & 46 & $2 \cdot 2$ \\
\hline $12 \cdot 0-14 \cdot 0$ & $\mathbf{0}$ & - & 10 & 0.48 \\
\hline All & 6641 & 100.000 & 2083 & $100 \cdot 00$ \\
\hline
\end{tabular}

*All ex-smokers of whom two admitted to having smoked within 24 hours of the test (COHb levels were $5 \cdot 1,5 \cdot 9,6 \cdot 5$, and $9 \cdot 0 \%$ ).

two of whom reported having smoked within 24 hours of the test!

Figure 1 shows the cumulative $\mathrm{COHb}$ distributions for men who smoked cigarettes only, pipes only, cigars only and non-smokers. The $\mathrm{COHb}$ levels of pipe and cigar smokers were similar and, in general, closer to the non-smoker levels than to those of the cigarette smokers, although the $5 \%$ of cigar smokers with the highest $\mathrm{COHb}$ levels had values very similar to those of the $5 \%$ of cigarette smokers with the highest levels.

Table 3 shows the percentage of non-smokers, cigarette smokers (including those who also smoked pipes and/or cigars), and the remaining pipe and/ or cigar smokers with $\mathrm{COHb}$ levels greater than or equal to specified cut-off levels.

\section{ALVEOLAR CARBON MONOXIDE AND} CARBOXYHAEMOGLOBIN

Figure 2 shows the relationship between alveolar breath $\mathrm{CO}$ concentration and $\mathrm{COHb}$ in 162 smokers and 25 non-smokers. A linear regression was performed, the equation for the regression line

Table 3 Percentage of non-smokers, cigarette smokers, and cigar and/or pipe smokers with $\mathrm{COHb}$ levels greater than or equal to specified cut-off levels

\begin{tabular}{|c|c|c|c|c|}
\hline \multirow[t]{2}{*}{ Smoking category } & \multicolumn{4}{|c|}{$\mathrm{COHb}$ cut-off level } \\
\hline & $1.5 \%$ & $2.0 \%$ & $2 \cdot 5 \%$ & $3.0 \%$ \\
\hline $\begin{array}{l}\text { Non-smokers } \\
\text { Cigarette smokers (including } \\
\text { men who also smoked pipes } \\
\text { and/or cigars) }\end{array}$ & $\begin{array}{l}3 \cdot 4 \\
86\end{array}$ & $\begin{array}{l}0.9 \\
81\end{array}$ & $\underset{75}{0 \cdot 3}$ & $\begin{array}{l}0 \cdot 2 \\
70\end{array}$ \\
\hline $\begin{array}{l}\text { Pipe and cigar smokers } \\
\text { (excluding men who also } \\
\text { smoked cigarettes) }\end{array}$ & 45 & 35 & 27 & 23 \\
\hline
\end{tabular}




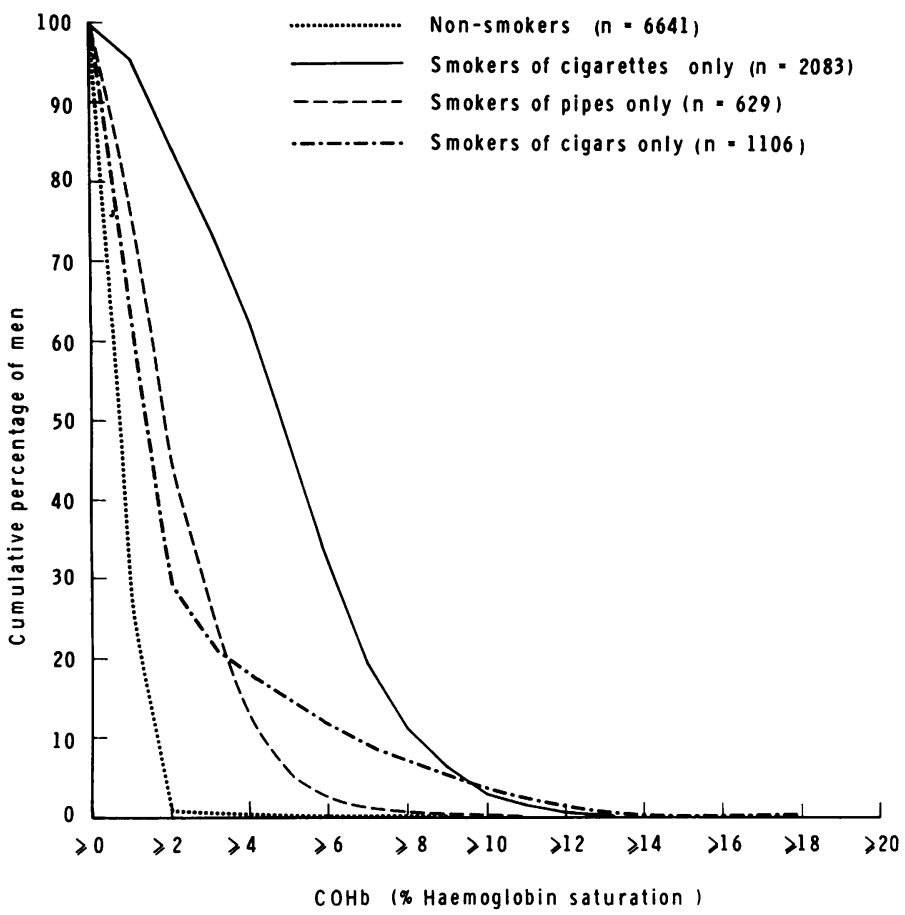

Fig 1 Cumulative distribution of $\mathrm{COHb}$ levels for men who smoked cigarettes only, pipes only, cigars only, and non-smokers (including both life-long non-smokers and ex-smokers).

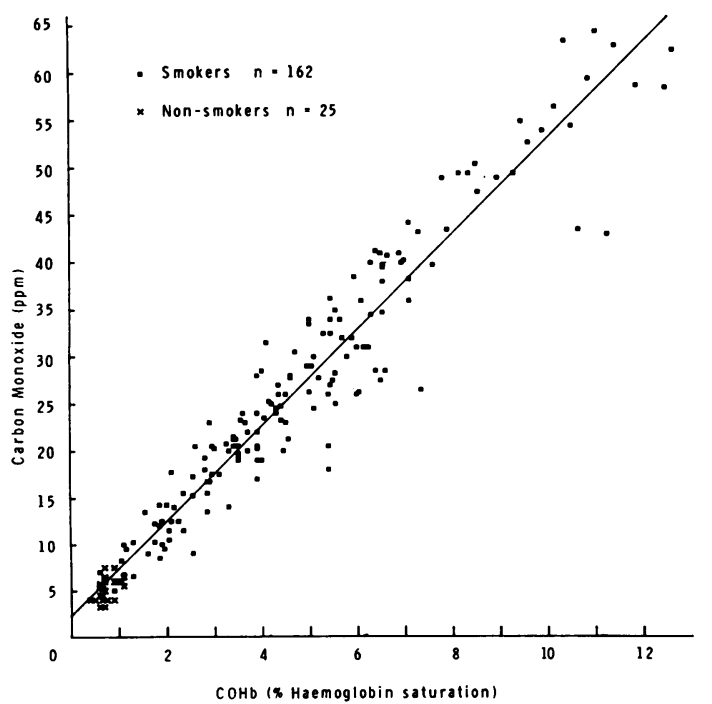

Fig 2 Relationship between alveolar gas $\mathrm{CO}$ concentration and $\mathrm{COHb}$.

being $\mathrm{CO}(\mathrm{ppm})=5.09 \times \mathrm{COHb}(\%$ haemoglobin saturation) $+2 \cdot 34$. The correlation coefficient was 0.97 . This high degree of correlation indicated that a $\mathrm{COH}$, level could be estimated reliably from an alveolar CO level, and the equation for this can be obtained from the same data, using a linear regression of $\mathrm{COHb}$ on $\mathrm{CO}$, giving $\mathrm{COHb}(\%$ haemoglobin saturation $)=0 \cdot 18 \mathrm{CO}(\mathrm{ppm})-0 \cdot 14$.

\section{Discussion}

The small overlap in the distribution of $\mathrm{COHb}$ levels from cigarette smokers and non-smokers was striking, and to some extent surprising in view of the short half-life of $\mathrm{COHb}$ in blood. ${ }^{8}$ The men were seen at the Medical Centre after 1100 hours and it is possible that if $\mathrm{COHb}$ estimations had been performed earlier in the day the discrimination between smokers and non-smokers would have been less clear.

Table 4 shows the probability of being a smoker for men with $\mathrm{COHb}$ levels equal to or greater than specified $\mathrm{COHb}$ cut-off levels, according to the percentage of cigarette smokers in the population assuming all smokers to be cigarette smokers. The probability that a man with a $\mathrm{COHb}$ level of greater than or equal to $2.5 \%$ is a smoker is greater than $98 \%$ for every smoking prevalence shown.

The correlation between alveolar $\mathrm{CO}$ concentration and $\mathrm{COHb}$ is very close, and the correlation coefficient $(0.97)$ is consistent with the results 
Table 4 Percentage probability of being a smoker with a $\mathrm{COHb}$ level equal to or greater than specified cut-off levels, in a population where smokers smoke cigarettes only

\begin{tabular}{lllll}
\hline $\begin{array}{l}\text { Percentage of cigarette } \\
\text { smokers in population }\end{array}$ & \multicolumn{4}{l}{ COHb cut-off level } \\
\cline { 2 - 5 } & $\geqslant 1.5 \%$ & $\geqslant 2.0 \%$ & $\geqslant 2.5 \%$ & $\geqslant 3.0 \%$ \\
\hline 20 & 86.6 & 95.9 & $98 \cdot 6$ & $99 \cdot 1$ \\
40 & 94.5 & $98 \cdot 4$ & $99 \cdot 5$ & $99 \cdot 7$ \\
60 & 97.5 & $99 \cdot 3$ & 99.8 & 99.9 \\
\hline
\end{tabular}

of previous studies. ${ }^{3910}$ The relationship between the two variables appears to be approximately linear, the regression equation differing only slightly from that obtained by other workers, ${ }^{111}$ and is in close agreement with that reported by Jones et al. ${ }^{10}$

Our study demonstrated that the Ecolyser is a simple method for measuring alveolar CO levels, provided precautions are taken to eliminate the possibility of false readings because of alcohol interference. The instrument, unlike the InfraRed Gas Analyser, is not sensitive to $\mathrm{CO}_{2}$ or water vapour, two factors which make it suitable for use on breath samples. The method is rapid and easy to perform, and enables a person's $\mathrm{COHb}$ level to be estimated while avoiding the discomfort and inconvenience of collecting blood. The use of the Ecolyser has previously been shown to discriminate well between smokers and nonsmokers. ${ }^{12}$ The $\mathrm{CO}$ results measured on an Ecolyser can be seen by the subject, which is likely to make it useful as a method of reinforcing medical advice to stop smoking-for example, in vascular clinics, in antenatal clinics, and perhaps even in general practice. It is also likely to be useful when judging the reliability of statements made about a man's smoking habits, and reference to table 3 will provide an approximate indication of whether a person is telling the truth.

We thank the Medical Research Council for part of our financial support. Jillian Boreham is a Laing Research Fellow in Preventive Medicine.

\section{References}

1 Ringold A, Goldsmith JR, Helwig HI, Finn R, Schuette F. Estimating recent carbon monoxide exposures. Arch Environ Health 1962; 5:308-18.

2 Cohen SI, Perkins NM, Ury HK, Goldsmith JH. Carbon monoxide uptake in cigarette smoking. Arch Environ Health 1971; 22:55-60.

3 Rea JN, Tyrer PJ, Kasap HS, Beresford SAA. Expired air carbon monoxide, smoking, and other variables. Br J Prev Soc Med 1973; 27: 114-20.

4 Goldsmith JR, Aronow WS. Carbon monoxide and coronary heart disease: a review. Environ Res 1975; 10:236-48.

5 Wald N, Howard S, Smith PG, Bailey A. Use of carboxyhaemoglobin levels to predict the development of diseases associated with cigarette smoking. Thorax 1975; 30:133-40.

6 McIlvaine PM, Nelson WC, Bartlett D. Temporal variation of carboxyhemoglobin concentrations. Arch Environ Health 1969; 19:83-91.

7 Wald N, Idle M, Bailey A. Carboxyhaemoglobin levels and inhaling habits in cigarette smokers. Thorax 1978; 33:201-6.

8 Coburn RF, Forster RE, Kane PB. Considerations of the physiological variables that determine the blood carboxyhemoglobin concentration in man. $J$ Clin Invest 1965; 44:1899-10.

9 Goldsmith JR, Landaw SA. Carbon monoxide and human health. Science 1968; 162:1352-9.

10 Jones RH, Ellicott MF, Cadigan JB, Gaensler EA. The relationship between alveolar and blood carbon monoxide concentrations during breathholding. J Lab Clin Med 1958; 51:553-64.

11 Rawbone RG, Coppin CA, Guz A. Carbon monoxide in alveolar air as an index of exposure to cigarette smoke. Clin Sci Mol Med 1976; 51: 495-501.

12 Coburn RF, Forster RE, Kane PB. Considerations of the physiological variables that determine the blood carboxyhemoglobin concentration in man. $J$ Clin Invest 1965; 44:1899-10.

13 Vogt TM, Selvin S, Widdowson G, Hulley SB. Expired air carbon monoxide and serum thiocyanate as objective measures of cigarette exposure. Am J Public Health 1977; 67:545-9. 